\title{
Confirmation of endotracheal tube depth using ultrasound in adults
}

\author{
Yansong Li, MD $\cdot$ Jing Wang, MD • \\ Xinchuan Wei, MD
}

Received: 28 January 2015/ Accepted: 3 March 2015/Published online: 12 March 2015

(C) Canadian Anesthesiologists' Society 2015

\section{To the Editor,}

We have read with great interest the article by McKay et al. ${ }^{1}$ It is a welcome investigation into the confirmation of endotracheal tube (ETT) depth using ultrasound. In the study, the correct placement of the ETT was determined when its tip was $>2.5 \mathrm{~cm}$ above the carina with the ETT cuff still below the cords. The ETT was fixed when its tip reached the sternal notch. As the manubriosternal joint is a well-known surface landmark for the carina, ${ }^{2}$ if the tip of the ETT is at the level of the sternal notch, it may be too far above the carina. Because the distance between the upper margin of the cuff and the tip is about $6.5 \mathrm{~cm}$ in adults, the cuff may be too close to the vocal cords. Several other studies, including those using ultrasound or palpation, have revealed that the depth of the ETT was correct when the cuff, rather than the tip, was placed at the sternal notch., As MacKay et al. did not record the position of the ETT cuff in their study, we are concerned that the cuff may have been too close to the vocal cords, thus increasing the risk of vocal cord impingement as well as unplanned extubation.

We have found it relatively easy to locate the position of the cuff and the vocal cords by ultrasound, and in so doing, if the ETT tip is far enough away from the carina, we can increase the ETT depth to keep the cuff away from the cords. We also agree with the view that subglottic damage by the ETT cuff can be minimized if the upper margin of the cuff is distal to the cricoid cartilage. This is because the membranous posterior wall of the tracheal rings may act to relieve the ETT cuff pressure if the cuff is overinflated, whereas the complete cricoid cartilage could not. ${ }^{5}$

Conflicts of interest None declared.

Funding Funded by the Department of Anaesthesiology, West China Hospital.

\section{References}

1. McKay WP, Wang A, Yip K, Raazi M. Tracheal ultrasound to assess endotracheal tube depth: an exploratory study. Can J Anesth 2015; DOI: 10.1007/s12630-015-0313-3.

2. Williams PL, Bannister LH, Berry MM, et al. Gray's Anatomy. The Anatomical Basis of Medicine and Surgery, 38th Edition. Edinburgh, Churchill Livingstone; 1995: 1677.

3. Uya A, Spear D, Patel K, Okada P, Sheeran P, McCreight A. Can novice sonographers accurately locate an endotracheal tube with a saline-filled cuff in a cadaver model? A pilot study. Acad Emerg Med 2012; 19: 361-4.

4. Pollard RJ, Lobato EB. Endotracheal tube location verified reliably by cuff palpation. Anesth Analg 1995; 81: 135-8.

5. Chong DY, Greenland KB, Tan ST, Irwin MG, Hung CT. The clinical implication of the vocal cords-carina distance in anaesthetized Chinese adults during orotracheal intubation. $\mathrm{Br} \mathrm{J}$ Anaesth 2006; 97: 489-95.

This letter is accompanied by a reply. Please see Can J Anesth 2015; 62: this issue.

Y. Li, MD · J. Wang, MD $\cdot$ X. Wei, MD ( $)$

Department of Anaesthesiology, West China Hospital, Cheng

Du, Sichuan, China

e-mail: weixinchuan@163.com 